\title{
PURIFICAÇÃO E CARACTERIZAÇÃO DA QUITINASE DE UVA (Vitis vinífera L. CV RED GLOBE) PARA A PRODUÇÃo DE QUITOSANA A PARTIR DE QUITINA DE CAMARÃO
}

\author{
Laidson Paes Gomes \\ Universidade Estadual da Zona Oeste, Av. Manuel Caldeira de Alvarenga, 1203. 23070-200 Rio de Janeiro - RJ. Brasil \\ Carlos Ivan Ribeiro de Oliveira, Márcia Cristina da Silva e Cristina Tristão de Andrade \\ Instituto de Macromoléculas Professora Eloísa Mano Universidade Federal do Rio de Janeiro, Centro de Tecnologia, Bl J. \\ Ilha do Fundão, 21941-909, Rio de Janeiro - RJ, Brasil \\ Eduardo Mere Del Aguila*, Joab Trajano Silva e Vânia M. Flosi Paschoalin \\ Instituto de Química, Universidade Federal do Rio de Janeiro, Av. Athos da Silveira Ramos, 149, 21941-909, Rio de Janeiro - RJ, Brasil
}

Recebido em 12/1/10; aceito em 30/6/10; publicado na web em 22/9/10

\begin{abstract}
PURIFICATION AND CHARACTERIZATION OF GRAPE (Vitis vinifera L. CV RED GLOBE) CHITINASES FOR PRODUCTION OF CHITOSAN FROM SHRIMP CHITIN. Chitinase is produced by a wide variety of plants as a defense against peste attacks. In this study, grape chitinases were purified 16 times by fractionation in $80 \%$ ammonium sulfate followed by dialysis and filtration. Purified chitinases exhibited enzymatic activity toward chitin azure. The yield of purified chitinase was $229 \mathrm{mg} / \mathrm{L}$ with chitinase activity of $563 \mathrm{U} / \mathrm{g}$. Chitinases had molecular masses of 24 and $30 \mathrm{kDa}$, as evaluated by SDS-PAGE $12.5 \%$. Two pH optima were determined 3.0 and 6.0. The optimal temperature was $42{ }^{\circ} \mathrm{C}$. Pre hydrolysis of crystalline shrimp chitin by chitinases caused in an increase in the deacetylation ratio triggered by chitin deacetylase producing chitooligosaccharides with DA (degree acetylation) of $58.8 \%$.
\end{abstract}

Keywords: grape chitinases; purification and characterization; chitin deacetylation.

\section{INTRODUÇÃO}

Os monossacarídeos formam uma grande variedade de estruturas poliméricas (oligossacarídeos e polissacarídeos), diferenciadas pelo tipo de monômero constituinte e pela forma como eles estão ligados ao longo do polímero, que desempenham funções como componentes estruturais, compostos de reserva e de reconhecimento e sinalização celular, por exemplo. As ligações glicosídicas presentes nestes polímeros podem ser clivadas por um grande número de enzimas pertencentes à superfamília de glicosil-hidrolases, composta por 115 famílias de hidrolases que atuam tanto sobre as ligações glicosídicas que unem monossacarídeos, quanto sobre as que unem carboidratos a outras biomoléculas. ${ }^{1,2}$

As quitinases (E.C. 3.2.1.14) são endoglicosil-hidrolases que clivam de forma específica as ligações glicosídicas da quitina, um homopolissacarídeo linear formado por unidades de 2-acetamida2-desoxi-D-glicose ( $\mathrm{N}$-acetil-D-glucosamina) unidas por ligações do tipo $\beta$-[1-4], encontradas principalmente nas carapaças de crustáceos, cutículas de insetos e na parede celular de fungos, sendo, depois da celulose, o biopolímero mais abundante na natureza. ${ }^{3}$ As quitinases estão distribuídas por entre duas númerosas famílias de glicosil-hidrolases (famílias 18 e 19), que diferem em relação às suas estruturas primárias e terciárias ${ }^{1}$ e ao mecanismo de catálise. ${ }^{4}$ As quitinases da família 18 formam produtos $\beta$-anoméricos, através de um mecanismo de retenção, enquanto as enzimas da família 19 formam produtos $\alpha$-anoméricos, por um mecanismo de inversão. ${ }^{5,6}$

As quitinases (Chase) de planta são independentemente classificadas, com base na presença de um domínio de ligação à quitina $\mathrm{e}$ na homologia de suas sequências de aminoácidos, em sete classes, nomeadas de I a VII. ${ }^{7}$ A maioria destas quitinases pertence à família 19, (classes I, II IV, VI e VII), com um pequeno número pertencente à família 18 (classes III e V), junto como as quitinases de fungos, animais e bactérias. ${ }^{8}$

\footnotetext{
*e-mail: emda@iq.ufrj.br
}

As quitinases são expressas constitutivamente em níveis relativamente baixos em todos os órgãos e tecidos das plantas, compartimentalizadas no vacúolo e apoplasto. ${ }^{9}$ As quitinases de plantas fazem parte do grupo de proteínas denominadas PR (proteínas relacionadas à patogenesis), capazes de induzir resistência, local ou sistêmica, ao ataque de fungos e outros fitopatógenos. ${ }^{10}$ Posteriormente, descobriuse que as proteínas PR (incluindo as quitinases) são também induzidas por vários outros estresses, como estiagem, salinidade, danos mecânicos, metais pesados e reguladores do crescimento vegetal. ${ }^{11-13}$

As quitinases constituem até $50 \%$ das proteínas solúveis em uvas (Vitis vinifera). ${ }^{14}$ Danos mecânicos aos tecidos da planta, ocasionados por fungos ou mastigação por insetos, provocam a liberação de uma variedade de hormônios vegetais, como etileno, que juntamente com o ácido salicílico estimulam a produção de quitinase. ${ }^{15,16}$ Durante o amadurecimento as uvas produzem níveis relativamente elevados de quitinase, provavelmente como uma forma de proteção contra o aumento da suscetibilidade de ataques por fungos, devido ao aumento da concentração de açúcares e ao amaciamento da casca do fruto. ${ }^{17}$ As quitinases parecem ter um papel direto na defesa do vegetal ao hidrolisar os polímeros de quitina, o principal componente da parede celular da maioria dos fungos. ${ }^{18}$

O crescente interesse na obtenção de oligossacarídeos biologicamente ativos tem aumentado o número de estudos usando a quitina e seus derivados. ${ }^{19}$ As quitosanas são polímeros de quitina parcialmente desacetilados, formadas por unidades 2-amino-2-desoxi-D-glicose (D-glucosamina) e 2-acetamida-2-desoxi-D-glicose (N-acetil-Dglucosamina) unidas por ligações $\beta-(1 \rightarrow 4)$. As quitosanas são biocompatíveis, biodegradáveis e não toxicas, ${ }^{20,21}$ apresentam atividades antimicrobiana, ${ }^{22}$ antitumoral, ${ }^{23}$ imunomoduladora, ${ }^{24}$ cicatrizante ${ }^{25} \mathrm{e}$ facilitadora de transporte através de membranas. ${ }^{26}$ Estes polímeros podem ser preparados como soluções de viscosidade controlada, géis, filmes e membranas, microesferas e nanopartículas, ${ }^{27}$ podem ser modificadas quimicamente, devido à presença de grupamentos reativos em sua estrutura. São usadas atualmente como emulsificante ${ }^{28}$ quelante de metais ${ }^{29}$ e como biofilmes comestíveis. ${ }^{30}$ A variação 
no grau de desacetilação e na massa molecular média deste polímero lhe confere propriedades funcionais diferenciadas.

As quitosanas podem ser encontradas naturalmente na parede celular de alguns fungos, mas são geralmente produzidas pela desacetilação não enzimática da quitina. Os métodos convencionais para a obtenção de quitosanas baseiam-se na hidrólise parcial da quitina em meio alcalino sob alta temperatura. Além de apresentarem baixo rendimento, estes processos causam quebras aleatórias no polímero, produzindo oligômeros com tamanho e grau de desacetilação variados. ${ }^{31} \mathrm{~A}$ utilização de catalisadores biológicos pode ser uma alternativa mais adequada para a produção de quitosanas com massa molar média e grau de desacetilação controlados. . $^{32,33}$

Oligômeros de quitosana com tamanho e grau de desacetilação controlados podem ser obtidos pela ação conjunta das enzimas quitina desacetilase (EC 3.5.1.41) e quitinase (EC 3.2.1.14). O uso da quitina desacetilase como método de desacetilação, em contraposição à hidrólise alcalina, evitaria a formação de subprodutos indesejáveis ${ }^{34} \mathrm{e}$ controlaria a cinética de produção dos polímeros de quitosanas com graus desejados de desacetilação.

O objetivo deste trabalho foi purificar e caracterizar as quitinases de uva (Vitis vinífera L. cv Red Globe). As enzimas obtidas apresentaram atividade catalítica e foram capazes de potencializar a desacetilação enzimática da quitina natural obtida do exoesqueleto de camarão.

\section{PARTE EXPERIMENTAL}

\section{Purificação parcial de quitinases (Chases)}

A polpa de $200 \mathrm{~g}$ de uvas (Vitis vinifera L. cv. Red Globe) foi homogeneizada na presença de $500 \mathrm{~mL}$ de tampão acetato de sódio $50 \mathrm{mmol} \mathrm{L}^{-1}$ (pH 5,0) em liquidificador doméstico. O homogeneizado foi centrifugado a $1700 \mathrm{x} \mathrm{g} \mathrm{a} 4{ }^{\circ} \mathrm{C}$ por $10 \mathrm{~min}$. As quitinases foram precipitadas pela adição de $\left(\mathrm{NH}_{4}\right)_{2} \mathrm{SO}_{4}$ ao sobrenadante $(0-80 \%$ de saturação), como descrito por Coelho..$^{35}$ Após $18 \mathrm{~h}$ a $4{ }^{\circ} \mathrm{C}$ a suspensão foi centrifugada a $5500 \mathrm{x} \mathrm{g} \mathrm{a} 4{ }^{\circ} \mathrm{C}$ por $20 \mathrm{~min}$, e o sedimento foi ressuspenso em $100 \mathrm{~mL}$ do mesmo tampão. A solução foi dialisada contra $3 \mathrm{~L}$ de água por $24 \mathrm{~h}$ a $4{ }^{\circ} \mathrm{C}$ (membrana com cut off de $10 \mathrm{kDa}$ ) e filtrada em membrana com poro de $0,22 \mu \mathrm{m}$ (Millex GS da Millipore).

\section{Dosagem da proteína}

A concentração de proteínas foi determinada usando-se kit Quibit Protein Assay (Invitrogen) conforme as recomendações do fabricante.

\section{Caracterização da preparação purificada SDS-PAGE}

A análise por SDS-PAGE 12,5\% foi realizada como descrita por Laemmli. ${ }^{36}$ As amostras foram precipitadas com $1 \mathrm{~mol} \mathrm{~L}^{-1}$ de ácido tricloroacético (TCA), o precipitado foi lavado por centrifugação com acetona gelada e o sedimento foi ressuspenso em tampão de amostra. As amostras contendo $20 \mu \mathrm{g}$ de proteína foram aplicadas ao gel que foi corado com Coomassie Brilliant Blue G-250 e documentado em um MiniBis Pro com o software GelCapture (DNR Bio-Imaging Systems).

\section{Determinação da atividade enzimática da quitinase}

A atividade da quitinase foi determinada como descrito anteriormente, ${ }^{37}$ usando quitina azure (Sigma-Aldrich, C-3020) como substrato. A mistura reacional era formada por $9 \mu \mathrm{g}$ de proteína, $200 \mu \mathrm{g}$ de quitina azure e tampão acetato de sódio $50 \mathrm{nmol} \mathrm{L}{ }^{-1} \mathrm{pH}$ 3,0 , no volume final de $700 \mu \mathrm{L}$. A reação foi incubada a $42{ }^{\circ} \mathrm{C}$ por 50 min e paralisada pela adição de $200 \mu \mathrm{L}$ de $\mathrm{HCl} 4 \mathrm{~mol} \mathrm{~L}^{-1}$. Após centrifugação a 12.000 x g por 5 min, a absorbância do sobrenadante foi quantificada a $550 \mathrm{~nm}$ em espectrofotômetro (Beckman DU 640). Uma unidade de quitinase foi definida como a quantidade de proteína capaz produzir o incremento de 1,0 de D.O. (Densidade óptica) a 550 $\mathrm{nm}$, por min, sob as condições descritas.

\section{Desacetilação da quitina de camarão}

Um miligrama de quitina de carapaça de camarão, cedida pelo laboratório de polímeros do Instituto de Macromoléculas (IMAUFRJ), após um processo de desmineralização, desproteinação e despigmentação ${ }^{38}$ de uma solução estoque em ácido fosfórico $60 \%$ ( $22 \mathrm{mg} / \mathrm{mL}$ ), foi tratada com $0,6 \mathrm{U}$ de quitinase de uva (Chase), em tampão acetato de sódio $50 \mathrm{nmol} \mathrm{L}{ }^{-1} \mathrm{pH} 3,0$ (volume final de $700 \mu \mathrm{L}$ ). A reação foi incubada a $42{ }^{\circ} \mathrm{C}$ por 50 min e paralisada pela adição de $200 \mu \mathrm{L}$ de $\mathrm{HCl} 4 \mathrm{~mol} \mathrm{~L}^{-1}$. A mistura reacional foi centrifugada (12.500 x g por $5 \mathrm{~min}$ ) e o sedimento ressuspenso em $600 \mu \mathrm{L}$ de tampão Tris-HCl $25 \mathrm{mmol} \mathrm{L}^{-1}$, pH 8,0 contendo $1 \mathrm{mg}$ de BSA. A esta mistura foram adicionadas $3 \mathrm{U}$ de quitina desacetilase de levedura (CD), purificada como descrito anteriormente. ${ }^{39}$ Após 1 e 2 h a 50 ${ }^{\circ} \mathrm{C}$, a reação foi paralisada a $100{ }^{\circ} \mathrm{C}$ por $10 \mathrm{~min}$.

A formação de aminas primárias foi usada como indicador da reação de desacetilação, ${ }^{40}$ usando um método desenvolvido em nosso laboratório. À mistura reacional era adicionada 1,0 mL de uma solução contendo 0,005\% de OPA (o-ftalaldeído - Invitrogen Life Technologies), $0,1 \%$ de etanol absoluto, $7 \mathrm{nmol} \mathrm{L}^{-1}$ de $\beta$-mercaptoetanol e 10 $\mathrm{mL}$ de tampão $\mathrm{Na}_{2} \mathrm{HCO}_{3} 50 \mathrm{nmol} \mathrm{L}{ }^{-1}, \mathrm{pH}$ 10,5. A reação foi incubada à temperatura ambiente por 2 min e a absorbância foi determinada a $340 \mathrm{~nm}$ em espectrofotômetro (Beckman DU 640). A quantidade de aminas primárias foi estimada por comparação com soluções de glicina de concentrações conhecidas, preparadas no mesmo tampão.

\section{Análises por FT-IR}

Os resultados da espectroscopia na região do infravermelho foram adquiridos por meio de análise realizada em espectrofotômetro FTIR 1720 (Perkin-Elmer, Massahusetts, USA) no modo de transmitância, com acúmulo de 20 vareduras e resolução de $2 \mathrm{~cm}^{-1}$. Cerca de $10 \mathrm{mg}$ de cada amostra foram secos, macerados e homogeneizados com aproximadamente $100 \mathrm{mg}$ de $\mathrm{KBr}$ para a formação de pastilhas usadas na aquisição de espectros.

Para a determinação do grau de acetilação, foram calculadas as absorbâncias nas bandas 1320 e $1420 \mathrm{~cm}^{-1}$. A banda localizada em $1320 \mathrm{~cm}^{-1}$ é característica para a $\mathrm{N}$-acetilglucoamina e refere-se aos grupos $-\mathrm{OH},-\mathrm{NH}_{2} \mathrm{e}-\mathrm{CO}$, tendo sido usada como referência. $\mathrm{O}$ valor da absorbância foi obtido por meio de cálculo da altura dos picos, referentes à linha base, previamente delimitadas. Nestes experimentos foram utilizadas $10 \mathrm{mg}$ de quitina natural de camarão, tratadas com $450 \mu$ g de quitinase purificada, seguido do tratamento com 50 $\mu \mathrm{g}$ de quitina desacetilase recombinante, nas condições de reação já descritas anteriormente para cada uma das enzimas.

A razão A1320/A1420 foi empregada para o cálculo do grau de acetilação (DA) de amostras de quitina e quitosana. ${ }^{41}$

\section{RESULTADOS E DISCUSSÃO}

Em 2003, a produção mundial de camarão foi de 4.630 .000 toneladas, sendo que $1.630 .000 \mathrm{t}(35,21 \%$ do total) foram produzidas por cultivo. ${ }^{42}$ No Brasil, a pesca extrativa marinha produziu $35.451,5$ toneladas de camarão em $2007 .{ }^{43}$ A carcinicultura, após um pico de produção de 90.190 t em 2003, manteve uma produção de $65.000 \mathrm{t}$ anuais de camarão no período de 2005 a $2007 .{ }^{44}$ O processamento de cerca de $100.000 \mathrm{t}$ anuais de camarão no Brasil gera uma enorme 
Tabela 1- Purificação de quitinases de Vitis vinifera L cv Red Globe

\begin{tabular}{lccccccc}
\hline Etapas de purificação & $\begin{array}{c}\text { Proteína } \\
(\mathrm{mg} / \mathrm{mL})\end{array}$ & $\begin{array}{c}\text { Volume } \\
(\mathrm{mL})\end{array}$ & $\begin{array}{c}\text { Proteína } \\
(\mathrm{mg})\end{array}$ & $\begin{array}{c}\text { Atividade total } \\
(\mathrm{mU})\end{array}$ & $\begin{array}{c}\text { Atividade especifica } \\
\left(\mathrm{mU} \mathrm{mg}^{1}\right)\end{array}$ & $\begin{array}{c}\text { Rendimento } \\
(\%)\end{array}$ & $\begin{array}{c}\text { Purificação } \\
\text { Extrato bruto }\end{array}$ \\
0,101 & 287 & 28,9 & 1030 & 35,6 & 100 & 1 \\
Sulfato de amônio $80 \%$ & 0,231 & 7 & 1,6 & 900 & 563 & 87 & 16 \\
\hline
\end{tabular}

O extrato bruto livre de células foi obtido da homogeneização de polpas de uva e precipitado com sulfato de amônia a 80\% de saturação. Uma unidade de enzima foi definida como a quantidade capaz de produzir absorbância igual a 1,0 por min por miligrama de proteína.

quantidade de rejeitos, principalmente durante a etapa de retirada da casca e do cefalotórax. Algumas das propostas para eliminar este resíduo da indústria pesqueira incluem a elaboração de farinha de casca de camarão (para a utilização em alimentos) e o aproveitamento da quitina para diversos usos, como na produção de catalisadores, em complementos alimentares para redução do colesterol e controle do peso, ou como agente imobilizador de enzimas e micro-organismos.

A transformação dos rejeitos da indústria de processamento do camarão em quitosanas com massas molares médias e níveis de desacetilação controlados seria uma alternativa viável, gerando produtos com alto valor agregado para usos alimentício, farmacêutico e biomédico, principalmente. Entretanto, quitosanas preparadas quimicamente não são geralmente consideradas para uso como materiais bioativos, devido à possibilidade de contaminação com compostos químicos tóxicos. ${ }^{33} \mathrm{~A}$ produção de quitosanas por ação de enzimas obtidas de organismos considerados GRAS (generally recognized as safe), como levedura e uva, certamente garantira a possibilidade de sua utilização tanto na indústria alimentícia como biomédica.

Neste trabalho, foi obtida uma preparação de quitinases de uva (Vitis vinifera $\mathrm{V}$. Red Globe) purificada por precipitação do extrato proteico bruto com sulfato de amônio a $80 \%$ de saturação. Usando o protocolo descrito, as quitinases de uva foram purificadas 16 vezes, com recuperação de $87 \%$ (Tabela 1). A preparação final continha 1,6 mg de proteínas e $900 \mathrm{mU}$ de quitinase. A análise da preparação por SDS-PAGE 12,5\% (Figura 1) revelou a presença de duas cadeias polipeptídicas, com massas moleculares de 24 e $30 \mathrm{kDa}$, determinadas com o uso do software GelQuant (DNR Bio-Imaging Systems). Os pesos encontrados são semelhantes com massas molares de 28 e $32 \mathrm{kDa}$ de duas quitinases da classe IV isoladas de uva, ${ }^{45}$ que têm a expressão dependente da fase de amadurecimento do fruto. ${ }^{17}$ As massas molares destas quitinases foram posteriormente determinadas por eletrospray MS como sendo $22.181 \mathrm{e}$ 25.450 Da, respectivamente, sendo a diferença entre as massas determinadas pelos dois métodos atribuída à migração anômala das proteínas PR em SDS-PAGE. ${ }^{17}$ As sequências de peptídeos isolados das duas proteínas apresentaram grande homologia com a sequência de dois cDNA homólogos que codificam quitinases da classe IV, isolados de uvas maduras, ${ }^{45}$ o que corrobora a hipótese da proteína menor ser derivada da maior por proteólise. ${ }^{17}$ As quitinases da classe IV em plantas possuem um domínio ligante de quitina, rico em cisteína, denominado de domínio heveina, em sua região $\mathrm{N}$-terminal, que é essencial para a ligação da quitina e para a afinidade pelo substrato. ${ }^{46}$

Tentativas de melhorar a etapa de precipitação, utilizando sulfato de amônio nas faixas de saturação de $0-20 \%, 0-40 \%$ e $0-60 \%$, não foram bem sucedidas, resultando em perda da atividade de interesse, sem ganho correspondente na purificação (resultados não apresentados). A atividade quitinase presente na preparação foi estabilizada pela adição de $20 \%$ de glicerol, que protege a preparação contra a desnaturação provocada por sucessivos congelamentos e descongelamentos.

A atividade quitinase manteve-se sob condições de velocidade inicial por até $50 \mathrm{~min}$ sob as condições de ensaio usadas (Figura 2A). A preparação purificada apresentou temperatura ótima de $42{ }^{\circ} \mathrm{C}$ (Figura 2B) e dois máximos de atividade, em pH 3,0 e 6,0 (Figura 2C), o que parece ser uma característica comum entre as quitinases. Por exemplo, as

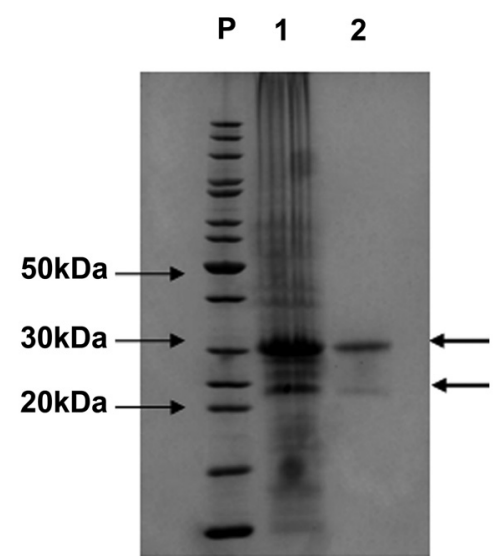

Figura 1. Análise da quitinase de uva por SDS-PAGE. As proteínas das diferentes frações foram precipitadas com TCA e analisadas por SDS-PAGE 12,5\%. Raia P, Padrão de massa molecular (PageRulerTM unstained protein ladder, Fermentas $\left.{ }^{\circledR}\right)$; raia 1, extrato bruto; raia 2, quitinase purificada

quitinases de folha de abacaxi são ativas na faixa de $\mathrm{pH} 3,0$ a 12,0, ${ }^{47} \mathrm{e}$ várias quitinases das famílias $18 \mathrm{e} 19$ podem apresentar dois $\mathrm{pH}$ ótimos. ${ }^{48}$

A enzima purificada foi usada para a produção de oligossacarídeos de quitosana. Uma preparação de $\alpha$-quitina isolada de carapaças de camarão foi tratada com $0,6 \mathrm{U}$ de quitinase (CHase) por 50 min a 42 ${ }^{\circ} \mathrm{C}$ e os oligômeros obtidos foram desacetilados com $3 \mathrm{U}$ de quitina desacetilase recombinante de levedura (CD). ${ }^{39}$ Foi verificado que o pré- tratamento da preparação com a quitinase purificada aumentou a eficiência da reação de desacetilação (Tabela 2).

Após 1 e 2 h de incubação foram produzidos 174,7 e 219,4 nmoles de aminas primárias, respectivamente, o que corresponde a 50 e 61 vezes mais do que na reação controle, na qual o pré-tratamento com a quitinase foi omitido (Tabela 2). Entretanto, a formação do produto de desacetilação não aumentou linearmente com o tempo, o que pode ter ocorrido pela instabilidade da enzima ou pela redução da quantidade do substrato no meio reacional, fazendo com que a enzima deixasse de trabalhar sob condições de velocidade inicial.

Na Figura 3, observa-se o espectro da quitina comparado a três amostras de quitosana submetidas à desacetilação enzimática. Neste caso, foi observada uma redução da banda em $1320 \mathrm{~cm}^{-1}$ das amostras que sofreram reação enzimática por 1 e $2 \mathrm{~h}$. No entanto, a amostra submetida à reação enzimática somente com a $\mathrm{CD}$ por $1 \mathrm{~h}$ não mostrou uma redução pronunciada nesta banda obtendo-se somente $1,30 \%$ de DA (Figura 3A).

Das amostras obtidas pela reação sequencial foi obtido o grau de acetilação, (DA) avaliado por FI-TR foi de 64,2\% para os quitooligossacarídeos tratados por $1 \mathrm{~h}$ e de $58,8 \%$ para aqueles tratados por $2 \mathrm{~h}$ (Figura 3B).

A pré-hidrólise da quitina com quitinase parece desfazer as interaçõs entre as moléculas da quitina cristalina obtida de camarão que são do tipo $\alpha$-quitina, correspondendo a um empacotamento denso resultante da disposição antiparalela das cadeias poliméricas, o que favorece a existência de númerosas ligações hidrogênio inter- e intra- 

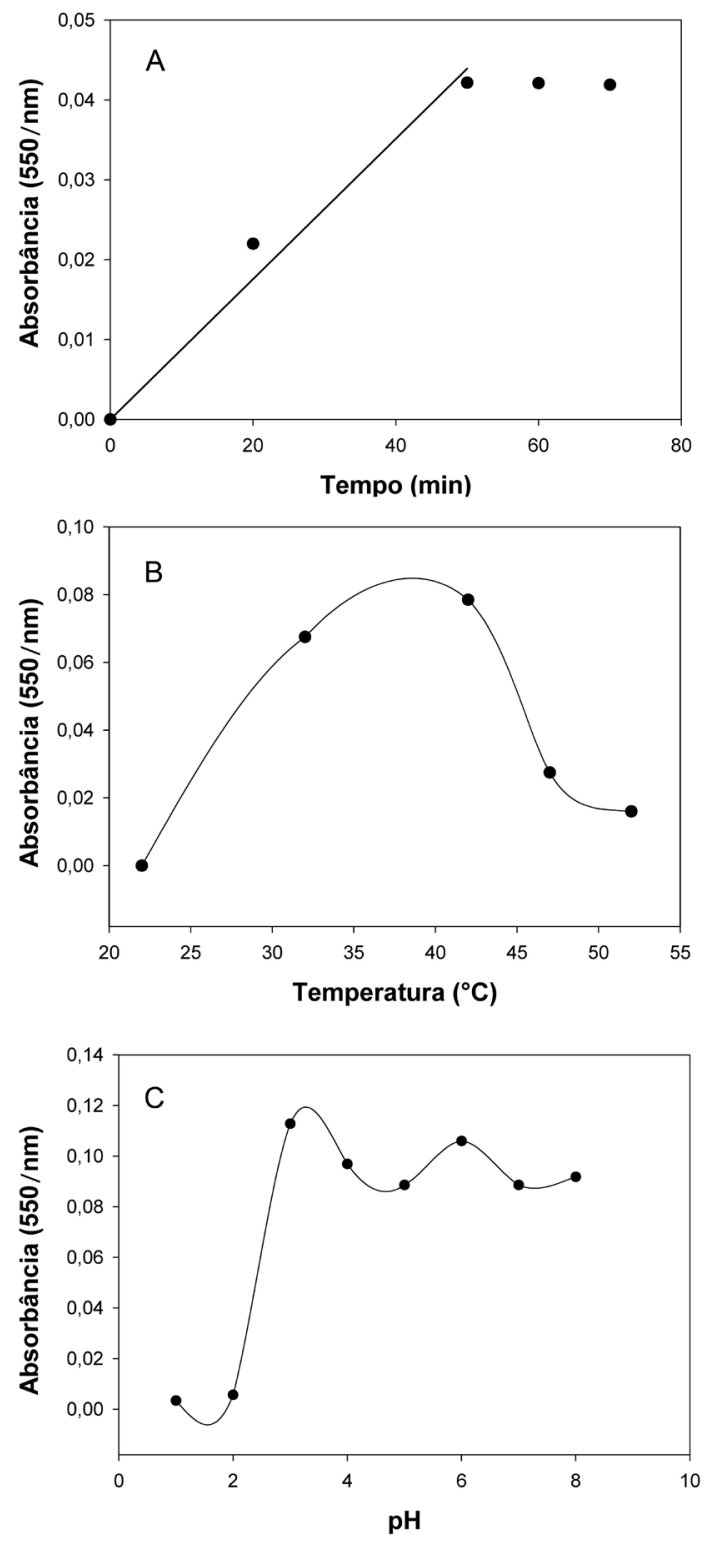

Figura 2. Caracterização da atividade da quitinase na fração purificada. A enzima purificada $(9 \mu \mathrm{g})$ foi incubada com $200 \mu \mathrm{g}$ do substrato cromogênico quitina azure (Sigma-Aldrich). (A) Efeito do tempo de incubação. (B) Efeito da temperatura. (C) Efeito do $\mathrm{pH}$

cadeias da mesma lamela e de lamelas vizinhas, formando estruturas rígidas e resistentes, o que poderia dificultar o acesso da enzima desacetilase recombinante aos grupos acetila do quito-oligossacarídeo. ${ }^{49}$ Um pré-tratamento para destruir esta estrutura cristalina, antes da reação de desacetilação, parece ser desejável para melhorar o grau de desacetilação, e produzir novos polímeros e oligômeros de quitosana, com tamanho molar e graus de desacetilação controlados.

Industrialmente, a quitosana é produzida pela hidrólise alcalina da quitina, que provoca quebras aleatórias das ligações glicosídicas. O processo apresenta baixo rendimento de oligômeros, alta produção de D-glucosamina, os oligômeros bioativos desejados podem estar contaminados por outros compostos químicos. ${ }^{33,50}$

Entre as hidrolases utilizadas para a obtenção de oligômeros de quitosanas estão celulase, lisozima, lipase, papaina, pectinase e proteinases de diferentes fontes. ${ }^{51}$ Entretanto, a utilização de hidrolases não específicas dificulta o controle da reação e da massa molar média final do produto, tendo sido obtidos, na maioria dos casos, oligômeros
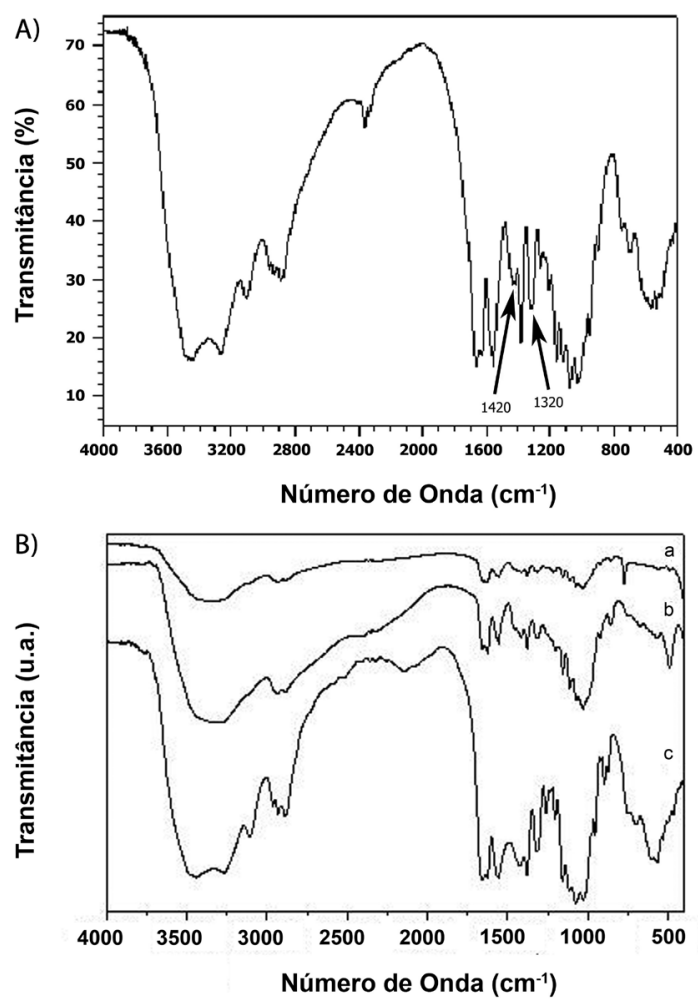

Figura 3. Espectros obtidas por FT-IR dos quitosanas obtidas enzimaticamente. A. Espectro da quitina tratada somente com CD por 1 h. B. Espectros dos produtos da reação enzimática sequencial com CHase e CD com diferentes intervalos de tempo. a) quitosana obtida pela tratamento com CHase e CD (1 h), b) quitosana obtida pela tratamento com CHase e CD (2 h) e c) quitina de camarão utilizada como substrato para os tratamentos enzimáticos

Tabela 2. Efeito do pré-tratamento da quitina de camarão com quitinases sobre a cinética de desacetilação

\begin{tabular}{ccc}
\hline Cinética de liberação de grupamentos amina (nmoles) & \\
\hline $\begin{array}{c}\text {-quitinase/ } \\
\text { +quitina desacetilase }\end{array}$ & $\begin{array}{c}\text { +quitinase/ } \\
\text { +quitina desacetilase }\end{array}$ & $\begin{array}{c}\text { +quitinase/ }^{\text {+quitina desacetilase }}{ }^{\mathrm{b}} \\
3,6\end{array}$ \\
\hline
\end{tabular}

Um miligrama de quitina de camarão foi submetido (+), ou não (-), a hidrólise com $0,6 \mathrm{U}$ de quitinases por $50 \mathrm{~min}$ a $42{ }^{\circ} \mathrm{C}$. Esta mistura foi incubada com quitina desacetilase por $1 \mathrm{~h}$ (a) ou $2 \mathrm{~h}$ (b) em um volume final de $600 \mu \mathrm{L}$. A desacetilação foi estimada pela quantificação dos grupamentos amina livre por método colorimétrico com o reagente OPA.

com massas maior que $10 \mathrm{kDa} .{ }^{51} \mathrm{~A}$ utilização de enzimas específicas (quitinases e quitina desacetilase) pode possibilitar a obtenção de oligômeros com massas molares médias e graus de desacetilação controlados, de acordo com as necessidades das aplicações finais, livres de subprodutos tóxicos e contaminantes.

\section{CONCLUSÕES}

Neste trabalho, a quitinase de uva foi purificada por um procedimento simples, rápido e com um alto rendimento. Esta preparação purificada revelou a presença de duas bandas proteicas compatíveis com os pesos moleculares das quitinases da classe IV expressas no fruto da videira. A enzima purificada apresentou atividade quitinolítica quando a quitina comercial foi usada como substrato.

$\mathrm{O}$ tratamento sequencial da quitina isolada de carapaças de 
camarão com a preparação de quitinase e a quitina desacetilase, recombinante purificada, aumentou não somente a eficiência da reação de desacetilação produzindo oligômeros de quitosanas como diminuiu o tempo necessário para a mesma.

A utilização de enzimas com estrita especificidade para o substrato (quitina) certamente garante a possibilidade de otimização das reações de hidrólise controlando a produção dos quito-oligossacarídeos. O produto final foi parcialmente caracterizado e os resultados obtidos indicam ser possível a produção de oligômeros de quitosana com tamanhos e graus de desacetilação definidos, para a utilização em aplicações específicas, padronizando cuidadosamente as condições da reação com as enzimas quitinase e quitina desacetilase.

\section{AGRADECIMENTOS}

Ao suporte financeiro da FAPERJ (Fundação Carlos Chagas Filho de Amparo à Pesquisa do Estado do Rio de Janeiro), CAPES (Conselho de Aperfeiçoamento de Pessoal de Nível Superior), CNPq (Conselho Nacional de Desenvolvimento Científico e Tecnológico) e FUJB (Fundação Universitária José Bonifácio).

\section{REFERÊNCIAS}

1. Henrissat, B.; Biochem. J. 1991, 280, 309.

2. Cantarel, B. L.; Coutinho, P. M.; Rancurel, C.; Bernard, T.; Lombard, V.; Henrissat, B.; Nucleic Acids Res. 2009, 37, D233.

3. Tharanathan, N. R.; Kitter, F. S.; Crit. Rew. Food Sci. Nutr. 2003, 43, 61.

4. Koga, D.; Mitsustomi, M.; Kono, M. S.; Matsumiya, M. Em Chitin and Chitinases; Jolles, P.; Muzzarelli, R. A. A., eds.; Birkhauser Verlag: Basel, 1999, p.111-124.

5. Sinnott, M. L.; Chem. Rev. 1990, 90, 1171

6. Perrakis, A.; Tews, I.; Dauter, Z.; Oppenheim, A. B.; Chet, I.; Wilson, K. S.; Vorgias, C. E.; Structure 1994, 2, 1169.

7. Neuhaus, J. M. Em Pathogenesis-Related Proteins in Plants; Datta, S. K.; Muthukrishnan, S., eds.; CRC Press: Boca Raton, 1999, p.77-98.

8. Iseli, B.; Armand, S.; Boiler, T.; Neuhaus, J. M.; Henrissat, B.; FEBS Lett. 1996, 382, 186.

9. Kasprzewska A.; Cell. Mol. Biol. Lett. 2003, 8, 809.

10. Frettinger, P.; Herrmann, S.; Lapeyrie, F.; Oelmuller, R.; Buscot, F.; Mycorrhiza 2006, 16, 219.

11. Kim, J. S.; Kim, Y. O.; Ryu, H. J.; Kwak, Y. S.; Lee, J. Y.; Kang, H.; Plant Cell Physiol. 2003, 44, 412.

12. Wiweger, M.; Farbos, I.; Ingouff, M.; Lagercrantz, U.; von Arnold, S.; J. Exp. Bot. 2003, 54, 2691.

13. Patel, A. K.; Singh, V. K.; Yadav, R. P.; Moir, A. J.; Jagannadham, M. V.; Plant Mol. Biol. 2009, 71, 277.

14. Waters, E. J.; Hayasaka, Y.; Tattersall, D. B.; Adams, K. S.; Williams, P. J.; J. Agric. Food. Chem. 1998, 46, 4950.

15. Derckel, J. P.; Legendre, L.; Audran, J-C.; Haye, B.; Lambert, B.; Plant. Sci. 1996, 119, 31.

16. Giannikis, C.; Bucheli C. S.; Skene, K. G. M.; Robinson, S. P.; SteeleScott, N.; Aust. J. Grape Wine Res. 1998, 4, 14.

17. Robinson, S. P.; Jacobs, A. K.; Dry, I. B.; Plant Physiol. 1997, 114, 771.

18. Collinge, D. B.; Kragh, K. M.; Mikkelsen, J. D.; Nielsen, K. K.; Rasmussen, U.; Vad, K.; Plant J. 1993, 3, 31.

19. Rinaudo, M.; Prog. Polym. Sci. 2006, 31, 603.

20. Roberts, G. A. F. Em Chitin Chemistry; Roberts, G. A. F., ed.; MacMillan Press Ltd: London, 1992, cap. 1.
21. Tanada-Palmu, P.; Proenca, P. S. P.; Trani, F. A. P.; Grosso, C. R. F.; Bragantia 2005, 64, 291.

22. Berger, J.; Reist, M.; Mayer, J. M.; Felt, O.; Gurny, R.; Eur. J. Pharm. Biopharm. 2004, 57, 35.

23. Usui, T. Em Oligosaccharides: Production, Properties and Applications; Nakakuki, T., ed.; Gordon and Breach Science Publishers: Switzerland, 1993, p.144-157.

24. Suzuki, S.; Watanabe, T.; Mikami, T.; Matsumoto, T.; Suzuki, M. Em Advances in Chitin and Chitosan; Brine, C. J.; Sanford, P. A.; Zikakis, J. P., eds.; Elsevier Applied Science: New York, 1992, p. 277-316.

25. Tsigos, I.; Martinou, A.; Kafetzopoulos, D.; Bouriotis, V.; Trends Biotechnol. 2000, 18, 305.

26. Buranapanitkit, B.; Srinilta, V.; Ingviga, N.; Oungbho, K.; Geater, A.; Ovatlarnporn, C.; Clin. Orthop. 2004, 424, 244.

27. Campana Filho, S. P.; Britto, D.; Curti, E.; Abreu, F. R.; Cardoso M. B.; Battisti, M. V.; Sim, P. C.; Goy, R. C.; Signini, R.; Lavall, R. L.; Quim. Nova 2007, 30, 644.

28. Kumar, M. N. V. R.; React. Funct. Polym. 2000, 46, 1.

29. Janegitz, B. C.; Oliveira, A.; Gomes, M. S.; Sartori, E. R.; Pereira-Filho, E. R.; Fatibello-Filho, O.; Quim. Nova, 2010, 33, 458.

30. Assis, O. B. G.; Silva, V. L.; Polímeros 2003, 13, 223.

31. Mathur, N. K.; Narang, C. K.; J. Chem. Educ. 1990, 67, 938.

32. Trudel, J.; Asselain, A.; Anal. Biochem. 1990, 189, 249.

33. Kim, S. K.; Rajapakse, N.; Carbohydr. Res. 2005, 62, 357.

34. Martinou, A.; Kafetzopoulos, D.; Bouriotis, V.; Carbohydr. Res. 1995, 273,235

35. Coelho, M. A. Z.; Tese de Doutorado, Universidade Federal do Rio de Janeiro, Brasil. 1993.

36. Laemmli, U. K.; Nature 1970, 227, 680.

37. Wirth, S. J.; Wolf, G. A.; J. Microbiol. Meth. 1990, 12, 197.

38. Percot, A.; Viton, C.; Domard, A.; Biomacromolecules 2003, 4, 12.

39. Del Aguila, E. M.; Tese de Doutorado, Universidade Federal do Rio de Janeiro, Brasil, 2006

40. Dorresteijn, R. C.; Berwal, L. G.; Zomer, G.; de Gooijer, C. D.; Wieten, G.; Beuvery, E. C.; J. Chromatogr., A 1996, 724, 159.

41. Brugnerotto, J.; Lizardi, J.; Goycoolea, F. M.; Arguelles-Monal, W.; Desbrieres, J.; Rinaudo, M.; Polymer 2001, 42, 3569.

42. Revista Panorama da Aquicultura 2004, 14, 21, http://www. panoramadaaquicultura.com.br., acessada em Janeiro 2010.

43. Estatística da Pesca 2007, Brasil Grandes Regióes e Unidades da Federação, Brasília- DF, Dezembro 2007.

44. Rocha, I. P.; Revista da ABCC 2008, 20.

45. Waters, E.; Shirley, N. J.; Williams, P. J.; J. Agric. Food. Chem. 1996, 44,3 .

46. Iseli, B.; Boller, T.; Neuhaus, J.-M.; Plant Physiol. 1993, 103, 221.

47. Taira, T.; Toma, N.; Ishihara, M.; Biosci. Biotechnol. Biochem. 2005, 69, 189.

48. Kawase, T.; Yokokawa, S.; Saito, A.; Fujii, T.; Nikaidou, N.; Miyashita, K.; Watanabe, T.; Biosci. Biotechnol. Biochem. 2006, 70, 988.

49. Campana-Filho, S. P.; de Britto, D.; Curti, E.; Abreu, F. R.; Cardoso, M. B.; Battisti, M. V.; Sim, P. C.; Goy, R. C.; Signini, R.; Lavall, R. L.; Quim. Nova, 2007, 30, 644.

50. Uchida, Y.; Izume, M.; Ohtakara, A. Em Chitin and chitosan: sources, chemistry, biochemistry, physical properties and applications.; SkjakBroek, G.; Anthonsen, T.; Sandford, P., eds., Elsevier Applied Science: London, 1989, p. 373-382.

51. Xie, Y.; Hua, J.; Weia, Y.; Honga, X.; Polym. Degrad. Stab. 2009, 94, 1895. 